\title{
The mouse Cat4 locus maps to Chromosome 8 and mutants express lens-corneal adhesion
}

\author{
J. Favor · P. Grimes · A. Neuhäuser-Klaus · \\ W. Pretsch $\cdot$ D. Stambolian
}

Received: 4 March 2008/Accepted: 5 March 2008/Published online: 12 April 2008

(C) Springer Science+Business Media, LLC 2008

\section{Erratum to: Mamm Genome (1997) 8(6):403-406 DOI 10.1007/s003359900456}

In the article "The mouse Cat4 locus maps to Chromosome 8 and mutants express lens-corneal adhesion", Mamm Genome 8, 403-406 (1997) by Favor J, Grimes P, Neuhäuser-Klaus A, Pretsch W, Stambolian D, we reported linkage of an eye abnormality locus defined by the Cat $4^{\mathrm{a}}$ mutation to $\mathrm{Chr} 8, \mathrm{cM} 31$. An attempt to more precisely map the locus showed no linkage to Chr 8 . We have conducted an independent genome-wide mapping analysis of the Cat $4^{\mathrm{a}}$ mutation, established linkage to $\mathrm{Chr} 2$, and identified $\mathrm{Cat}^{\mathrm{a}}{ }^{\mathrm{a}}$ to be a missense mutation in Pax6 (Favor et al., submitted). We have sequenced DNA from $\mathrm{Cat}^{\mathrm{a}}$ tissues archived before the initiation of the mapping studies reported in Favor et al. (1997) as well as from three independent $\mathrm{Cat}^{\mathrm{a}}{ }^{\mathrm{a}}$ mutant lines established prior to the initiation of the mapping studies reported in Favor et al. (1997) and maintained to date, and confirmed the Pax6 missense mutation in all mutation carriers. Thus, $\mathrm{Cat}^{\mathrm{a}}{ }^{\mathrm{a}}$ is a member of the Pax6 allelic series.

\section{Reference}

Favor J, Gloeckner CJ, Neuhäuser-Klaus A, Pretsch W, Sandulache R, Saule S, Zaus I. Relationship of Pax6 activity levels to the extent of eye development in the mouse, Mus musculus. Genetics (submitted)

P. Grimes-deceased.

The online version of the original article can be found under doi: $10.1007 / \mathrm{s} 003359900456$.

J. Favor $(\varangle) \cdot$ A. Neuhäuser-Klaus · W. Pretsch Institute of Human Genetics, Helmholtz Center Munich, Ingolstädter Landstrasse 1, 85764 Neuherberg, Germany e-mail: favor@helmholtz-muenchen.de

P. Grimes · D. Stambolian

Scheie Eye Institute and Department of Ophthalmology, School of Medicine, University of Pennsylvania, Philadelphia, PA 19104, USA

D. Stambolian Department of Genetics, School of Medicine, University of Pennsylvania, Philadelphia, PA 19104, USA 